American Journal of Applied Sciences 7 (6): 724-731, 2010

ISSN 1546-9239

(C) 2010Science Publications

\title{
Surface Modification of Polystyrene Beads by Ultraviolet/Ozone Treatment and its Effect on Gelatin Coating
}

\author{
${ }^{1}$ A.N. Yusilawati, ${ }^{1}$ M. Maizirwan, ${ }^{1}$ M.S. Hamzah, ${ }^{2}$ K.H. Ng and ${ }^{3}$ C.S. Wong \\ ${ }^{1}$ Department of Biotechnology Engineering, Faculty of Engineering, \\ International Islamic University Malaysia, Kuala Lumpur, Malaysia \\ ${ }^{2}$ School of Arts and Science, Tunku Abdul Rahman College, Kuala Lumpur, Malaysia \\ ${ }^{3}$ Plasma Research Laboratory, Department of Physics, Faculty of Science, \\ University of Malaya, Kuala Lumpur, Malaysia
}

\begin{abstract}
Problem statement: Polystyrene failed to provide any reactive functionality of surface hydrophilicity that is capable of binding proteins. It is known that polystyrene must be chemically modified to make its surface amenable to covalent crosslinking with protein. Approach: The aim of this study was to investigate the effects of UV/ozone treatment on gelatin coating. The surfaces of microsize polystyrene beads $(150 \mu \mathrm{m})$ were modified by UV/ozone treatment system at different treatment time, ozone flow-rate and UV intensity was analyzed by Design expert software. The treated beads were characterized with ATR-FTIR analysis to determine the introduction of carbonyl $(-\mathrm{C}=\mathrm{O})$, carboxylic group $(-\mathrm{COOH})$ and amide group $\left(-\mathrm{CO}-\mathrm{NH}_{2}\right)$ onto the polystyrene surface. Sample characterization was also carried out by SEM and densitometer. Gelatin immobilization was then preceded by incubating treated PS sample in gelatin solution and the total amount of gelatin coated on the modified surface was identified by Bradford assay. Results: The maximum amount of gelatin obtained was $63.75 \mu \mathrm{g} \mathrm{mL}^{-1}$ while the lowest amount obtained for untreated PS $\left(9.947 \mu \mathrm{g} \mathrm{mL}^{-1}\right)$. The introduction of carbonyl, hydroxyl and amide group on the polystyrene beads surface was confirmed by ATR-FTIR analysis and thus measures the importance of UV/ozone treatment. Conclusion: From the results, it has been found that time is the most significant factor to prepare samples for gelatin immobilization at reduced flow rate and at an increased Ultraviolet (UV) intensity in the ranges of study.
\end{abstract}

Key words: Polystyrene, immobilized, gelatin, protein, UV/ozone

\section{INTRODUCTION}

Immobilized proteins are used in many biochemical applications and often the amount of protein attached to the surface must be determined (Orschel et al., 1998). Gelatin is particularly important for engineering cellsurface properties because it is one of the most commonly occurring proteins in the human body and one that plays a central role in the formation of extracellular matrix with which cells have extensive communication (Mao et al., 2003; Kang et al., 1999) depositing gelatin onto the surface of solid substrates is a useful technology to modify the surface properties of in vitro cell culture scaffolds, presenting a suitable adhesion signal for many cell types (Mengyan et al., 2005). Immobilization of gelatin means gelatin is physically confined or localized in a certain defined region of space with retention of their catalytic activities, which can be used repeatedly and continuously (Chibata, 1979). Thus it allows gelatin to be held in the core throughout the reaction, following which they can be easily separated from cells which is considered to be reusable and more efficient. However, it is well known that adsorption of protein is affected by wet ability of surfaces on substrates. Polymer particles can be covalently binding with gelatin either directly or indirectly by the aid of cross linking agent. Polymers which make covalent bonding directly with gelatin include monomers with an active halogen atom, epoxies and compounds containing aldehyde group. On the other hand, polymers are also capable of making covalent bonding with gelatin through the use of a cross linking agent which includes carboxylic acid containing group, amine containing monomers and active methylene group containing monomers.

Polystyrene (PS) is a widely used polymer as a core substrate because of its favorable properties such as low specific weight, high chemical resistance and

Corresponding Author: A.N. Yusilawati, Department of Biotechnology Engineering, Faculty of Engineering,

International Islamic University, Kuala Lumpur, Malaysia 
mechanical flexibility and also it is biocompatible (Murakami et al., 2005). PS as biomaterials has been studied and manufactured for cell attachment. However, the adhesion of gelatin on unmodified PS surfaces is generally poor (Goddard and Hotchkiss, 2007; Saltzman and Kyriakides, 2007). UV-ozone has been shown to be a highly successful method for the controlled modification of polymers for applications ranging from adhesion and wetting improvement to the production of surfaces for enhanced cell attachment. This approach has previously been used to increase the surface oxygen, surface polarity and wet ability for a number of polymers in studies relating to adhesion and wetting. UV-ozone also has many advantages over the alternative methods of surface modification namely: no vacuum systems are required and it can give precise control over the modification process. Absence of any wet chemistry means that there are no residual solvents or other contaminants (Murakami et al., 2003; Teare et al., 2001). Furthermore, the technique itself does not require a sophisticated apparatus, it is quick and easy to use and the oxidation is controllable (Teare et al., 2001). Ozonation treatment with UV light can easily be carried out in various gas, solvent and solution media at room temperature without a vacuum system and is suitable for heat-unstable materials such as organic substrates (Murakami et al., 2003; Clark Jr et al., 2000; Davidson et al., 2004).

\section{MATERIALS AND METHODS}

About $3 \mathrm{~g}$ of untreated $150 \mu \mathrm{m}$ PS beads (Cat. no LS340120 SDS) were obtained from Goodfellow (UK), pure oxygen gas $(99 \%)$ were supplied by MOX linde Sdn Bhd (Malaysia), Coomassie Brilliant blue G250 (Cat. no. C.I 42655) was purchased from Merck (Germany). Acetone, ethanol, bovine gelatin and other chemicals were supplied by Sigma (St. Louis, USA).

Sample treatment: The system for the surface modification of the PS particle was built using the system as suggested by Murakami et al. (2005) but with a slight modification. Before usage, the polystyrene particles were washed in ethanol solution to remove any contaminants present on the surface. After several washing cycles the solvent was removed by vacuum filtration and the PS particles were allowed to dry. About $3 \mathrm{~g}$ PS particles were placed in a Dresher bottle (Quickfit ${ }^{\circledR}$ ) and were ozonated at different flow rates, exposure time and UV intensities. UV was irradiated from both sides with three $6 \mathrm{~W}$ low-pressure mercury lamps (UV lamps) at a wavelength of $254 \mathrm{~nm}$ and at a constant radiation of $22 \mathrm{~m} \mathrm{~W} \mathrm{~cm}^{-2}$ and maintaining a distance of $10 \mathrm{~cm}$ from the UV lamps. Ozone was produced by silent discharge of oxygen (purity of $99.9 \%)$.

Experimental design: The purpose of experimental design was to identify the significance of the treatment condition for the immobilization of gelatin. Box Behnken model under Response Surface Method (RSM) was used to elucidate optimal conditions for gelatin immobilization on the treated surface using Design Expert®6.0.8 software. Three independent variables selected in these studies are exposure time (A, $\mathrm{min})$, flowrate $\left(\mathrm{B}, \mathrm{L} \mathrm{min}^{-1}\right)$ and UV intensity $(\mathrm{C}, \mathrm{W})$ with three levels for each of these parameters as indicated in Table 1. Gelatin concentration was selected as dependent output variable $\left(\mathrm{Y}, \mu \mathrm{g} \mathrm{mL}^{-1}\right)$ to determine the significance of each factor under study.

Gelatin coating: Immobilization of gelatin was performed according to Shen et al. (2007) by immersing, respectively the UV/ozone treated PS samples in $3.0 \mathrm{~g} \mathrm{~L}^{-1}$ of gelatin solution in PBS (pH 7.4) for $2 \mathrm{~h}$ under $37^{\circ} \mathrm{C}$ in an incubator shaker (Inforce HT). The samples were then washed by PBS (pH 7.4) and subsequently rinsed by distilled water for three times. All the samples were then dried for $3 \mathrm{~h}$ at temperature of $60^{\circ} \mathrm{C}$.

Quantifying immobilized gelatin: Immobilized gelatin was analyzed by the method suggested by Gosnell and Mottola (1988) and $\mathrm{Lu}$ et al. (2007). $50 \mathrm{mg}$ of covalently coated polystyrene was covered with $200 \mu \mathrm{L}$ of the Coomasie blue dye solution and the sample was shaken for $30 \mathrm{~min}$ at room temperature and rinsed with the washing solution to remove the dye which was not bound to the immobilized proteins. Afterwards, the protein bound dye was removed with $220 \mu \mathrm{L} 0.1 \mathrm{M}$ sodium hydroxide solution in $80 \%$ methanol, by shaking for $5 \mathrm{~min}$ at room temperature. $100 \mu \mathrm{L}$ of this solution was placed into micro titer plate (Greiner, Germany) and acidified with $20 \mu \mathrm{L}$ of $4 \mathrm{M}$ hydrochloric acid. The samples were then measured immediately at $630 \mathrm{~nm}$ and the obtained data were compared with BSA standard curve.

Table 1:Factors and levels used in $3^{3}$ box Behnken designs for UV/ozone treated PS surface

\begin{tabular}{llllrr}
\hline & & \multicolumn{4}{c}{ Uncoded level } \\
Variables & Unit & Symbol & \multicolumn{1}{l}{-1} & \multicolumn{1}{c}{0} & \multicolumn{1}{c}{1} \\
\hline Time & min & $\mathrm{A}$ & 30.0 & 45.0 & 60.0 \\
Flow rate & $\mathrm{L} \mathrm{min}{ }^{-1}$ & $\mathrm{~B}$ & 1.0 & 1.5 & 2.0 \\
UV intensity & $\mathrm{W}$ & $\mathrm{C}$ & 6.0 & 12.0 & 18.0 \\
\hline
\end{tabular}


Sample characterization: Evaluation of the physically modified gelatin coated PS particles was carried out by measuring the FT-IR (Perkin Elmer) spectra using the Attenuated Total Reflection method (ATR/IR) in the region of $550-4000 \mathrm{~cm}^{-1}$ to determine the existing functional group. The structure and morphology of untreated and treated samples as well as covalently gelatin coated was also observed using SEM (JEOL, JSM 5600). Furthermore, the densities of the samples were also measured using densitometer which is based on Archimedes principle (ERLA) by first forming the powder into pellet using Single-punch Uniaxial Hydraulic Compactor (Carver).

\section{RESULTS}

Process condition for PS modification: Fifteen samples were run according to the Box Behnken design under Response Surface Method (RSM). Amount of gelatin immobilized on PS surface was measured to determine the best condition for surface modification. The low (-1), medium (0) and high $(+1)$ level values have already been shown in Table 1 . The effects of time (A) ozone flowrate (B) and UV intensity (C) on the amount of immobilized gelatin were analyzed by statistical software Design Expert, giving the main effects, the variance and the interaction between the effects acting in the coating of bovine gelatin on UV/ozone modified PS particles. Data obtained in Table 2 was measured for three replicates. From Table 2, it could be seen that Run $12\left(66.84 \mu \mathrm{g} \mathrm{mL} L^{-1}\right)$ obtained higher immobilized amount of gelatin on the PS surface followed by Run $2\left(59.05 \mu \mathrm{g} \mathrm{mL}^{-1}\right)$ and Run $6(52 \mu \mathrm{g}$ $\mathrm{mL}^{-1}$ ). On the other hand, the lowest amount of gelatin measured for untreated sample followed by Run 10 $\left(26.84 \mu \mathrm{g} \mathrm{mL}^{-1}\right)$ and Run $11\left(28.89 \mu \mathrm{g} \mathrm{mL}^{-1}\right)$. Compared to treated PS particle, untreated PS particle contain very less amount of gelatin $\left(9.947 \mu \mathrm{g} \mathrm{mL}^{-1}\right)$ as reported in Table 2. The developed regression model was evaluated by analyzing the values of regression coefficients, Analysis Of Variance (ANOVA), p-and F-values. The quality of fit of the polynomial model equation was expressed by the coefficient of determination, $\mathrm{R}^{2}$. According to Table 3, the Model F-value of 5.45 implies that the model is significant with a low pvalue $(\mathrm{p}<0.05)$. Values of Prob $>\mathrm{F}$ less than 0.0500 indicate model terms are significant. In this case $\mathrm{A}, \mathrm{A}^{2}$ are significant model terms with variables that were highly significant were the linear effect of time $(\mathrm{p}<0.01)$, while other terms were not significant ( $p>0.05$ ). On the other hand, $R^{2}$ is $90.23 \%$, adj $R^{2}$ is $72.65 \%$ and Adequate Precision is 7.653 indicate an adequate signal to noise ratio and this model can be used to navigate the design space (Bari et al., 2009). Developed model for predicting the optimal values of gelatin concentration within the experimental constrains in terms of coded factors are:

$\mathrm{Y}\left(\right.$ gelatin $\left.\mu \mathrm{g} \mathrm{mL}^{-1}\right)=48.16+9.50 \mathrm{~A}$

$-3.19 \mathrm{~B}+3.07 \mathrm{C}-10.02 \mathrm{~A}^{2}+2.57 \mathrm{~B} 2$

$+4.23 \mathrm{C}^{2}-3.27 \mathrm{AB}+0.46 \mathrm{AC}-4.78 \mathrm{BC}$

$\mathrm{R}^{2}$ value indicates that $90 \%$ of the variables (time, flowrate and UV intensity) contribute very positively to the response. The design suggested the maximum amount of gelatin $\left(67.635 \mu \mathrm{g} \mathrm{mL}^{-1}\right)$ can be obtained when the sample time is $55.17 \mathrm{~min}$, flowrate is 1.01 deduced that to obtain maximum gelatin amount with $\mathrm{L} \min ^{-1}$ and UV intensity is $(17.81 \mathrm{~W})$. The software minimum value of variable factors, $47.117 \mu \mathrm{g} \mathrm{mL}^{-1}$ immobilized gelatin can be obtained. Figure 1 showed the interaction between available terms.

Table 2: Design of experiment and response value Box Behnken design, 1 block, 3 centre point, 15 runs (Spreadsheet 1)

\begin{tabular}{lrrrll} 
& & & & & \\
Standard & & $\mathrm{B}$ & & & \\
run & $\mathrm{A}(\mathrm{min})$ & $\left(\mathrm{L} \mathrm{min}^{-1}\right)$ & $\mathrm{C}(\mathrm{W})$ & Actual & Predicted \\
\hline 1 & 0 & 1 & -1 & 49.63 & 52.73 \\
2 & 1 & -1 & 0 & 59.05 & 56.29 \\
3 & 1 & 1 & 0 & 48.03 & 44.11 \\
4 & 1 & 0 & -1 & 47.89 & 48.71 \\
5 & 0 & 0 & 0 & 48.12 & 48.16 \\
6 & 0 & 1 & 1 & 52.00 & 50.06 \\
7 & 0 & 0 & 0 & 48.16 & 48.16 \\
8 & -1 & 0 & 1 & 35.92 & 35.10 \\
9 & 0 & -1 & -1 & 48.37 & 50.31 \\
10 & -1 & -1 & 0 & 26.84 & 30.76 \\
11 & -1 & 1 & 0 & 28.89 & 31.65 \\
12 & 0 & -1 & 1 & 66.84 & 63.75 \\
13 & -1 & 0 & -1 & 36.50 & 30.64 \\
14 & 1 & 0 & 1 & 49.16 & 55.02 \\
15 & 0 & 0 & 0 & 48.20 & 48.16 \\
Untreated & & & & 9.947 & 9.947 \\
\hline
\end{tabular}

Table 3: Analysis Of Variance (ANOVA) for the model

\begin{tabular}{lrrl}
\hline Source & Sum of squares & F-value & P-value \\
\hline Model & 1399.27 & 5.450 & 0.0382 \\
$\mathrm{~A}$ & 721.62 & 25.290 & 0.0040 \\
$\mathrm{~B}$ & 63.56 & 2.230 & 0.1958 \\
$\mathrm{C}$ & 57.94 & 2.030 & 0.2135 \\
$\mathrm{~A}^{2}$ & 343.84 & 12.050 & 0.0178 \\
$\mathrm{~B}^{2}$ & 17.75 & 0.620 & 0.4660 \\
$\mathrm{C}^{2}$ & 54.94 & 1.930 & 0.2239 \\
$\mathrm{AB}$ & 42.71 & 1.500 & 0.2757 \\
$\mathrm{AC}$ & 0.86 & 0.030 & 0.8693 \\
$\mathrm{BC}$ & 64.80 & 2.270 & 0.1922 \\
\hline $\mathrm{p}<0.05$ indicate & & the
\end{tabular}

$\mathrm{p}<0.05$ indicate the model terms are significant; $\mathrm{p}<0.01$ indicate the model terms are highly significant 
The 3D response surface is the graphical representation of the regression equation used to determine the optimum values of the variables within the ranges considered (Murakami et al., 2003). From the interaction figure (Fig. 1), the maximum production was obtained at the point of intersection of the major and minor axes of the ellipse.

Correlation between density and gelatin immobilization: The density of the sample before and after gelatin coating was evaluated as in Table 4. It was observed that the density of the PS particles were decreased after UV/ozone surface modification with the lowest density obtained for run $1\left(1.007 \mathrm{~g} \mathrm{~cm}^{-3}\right)$ and the highest density obtained for run 3 and $13\left(1.020 \mathrm{~g} \mathrm{~cm}^{-3}\right)$ compared to untreated PS sample which is $1.048 \mathrm{~g} \mathrm{~cm}^{-3}$. However, it was observed that a slight change in treatment condition has no significant effect on sample density as the value is close with each other. After gelatin coating, it was shown that the density was increased due to immobilization of bovine gelatin on the modified PS surfaces. Run 12 has the highest density difference $\left(0.014 \mathrm{~g} \mathrm{~cm}^{-3}\right)$ while Run 10 and Run 11 have the lowest density difference $\left(0.007 \mathrm{~g} \mathrm{~cm}^{-3}\right)$. Density difference of PS particle before and after gelatin coating was parallel with measured gelatin content in Table 1. This indicates that gelatin was successfully immobilized on the modified PS surface compared to untreated PS with no change in density.

Fourier transforms infrared spectroscopy analysis: Figure 2 and 3 show only selected samples (untreated, Run 2, 11, 13 and 12) with higher and lower amount of gelatin and these data confirmed the results obtained in Table 2.

Table 4: Sample density before and after coating

\begin{tabular}{llll}
\hline Run & $\begin{array}{l}\text { Density after } \\
\text { UV/ozone } \\
\text { treatment }\left(\mathrm{g} \mathrm{cm}^{-3}\right)\end{array}$ & $\begin{array}{l}\text { Density after } \\
\text { gelatin coating } \\
\left(\mathrm{g} \mathrm{cm}^{-3}\right)\end{array}$ & $\begin{array}{l}\text { Difference } \\
\text { in density }\end{array}$ \\
\hline 1 & 1.007 & 1.019 & 0.012 \\
2 & 1.011 & 1.023 & 0.012 \\
3 & 1.020 & 1.031 & 0.011 \\
4 & 1.014 & 1.025 & 0.011 \\
5 & 1.017 & 1.028 & 0.011 \\
6 & 1.015 & 1.027 & 0.012 \\
7 & 1.017 & 1.029 & 0.012 \\
8 & 1.012 & 1.020 & 0.008 \\
9 & 1.015 & 1.024 & 0.009 \\
10 & 1.018 & 1.025 & 0.007 \\
11 & 1.016 & 1.023 & 0.007 \\
12 & 1.012 & 1.026 & 0.014 \\
13 & 1.020 & 1.028 & 0.008 \\
14 & 1.015 & 1.027 & 0.012 \\
15 & 1.017 & 1.029 & 0.012 \\
Untreated & 1.048 & 1.048 & 0.000 \\
\hline
\end{tabular}
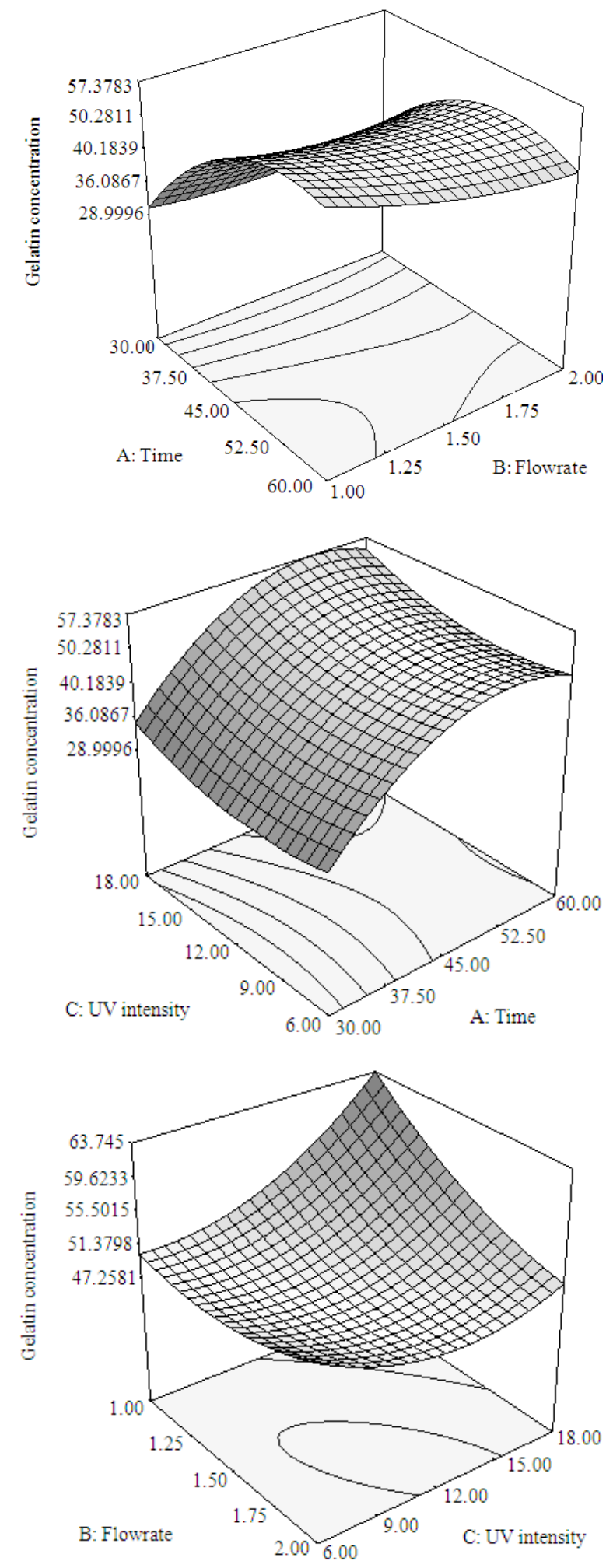

Fig. 1: 3D response surface shows the interaction between the independent variables 
Am. J. Applied Sci., 7 (6): 724-731, 2010

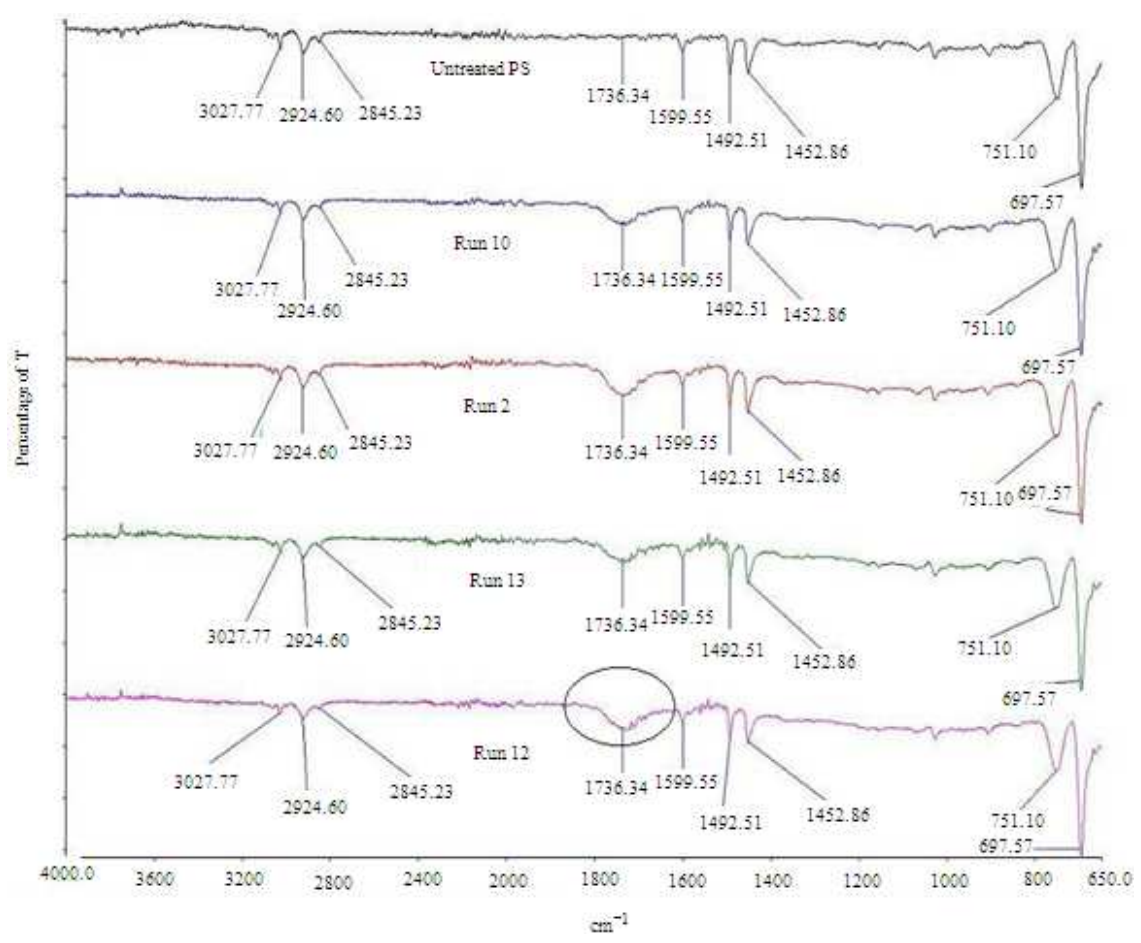

Fig. 2: FTIR of selected run of PS particle after UV/ozone surface modification for untreated PS, Run 10, 2, 13 and 12

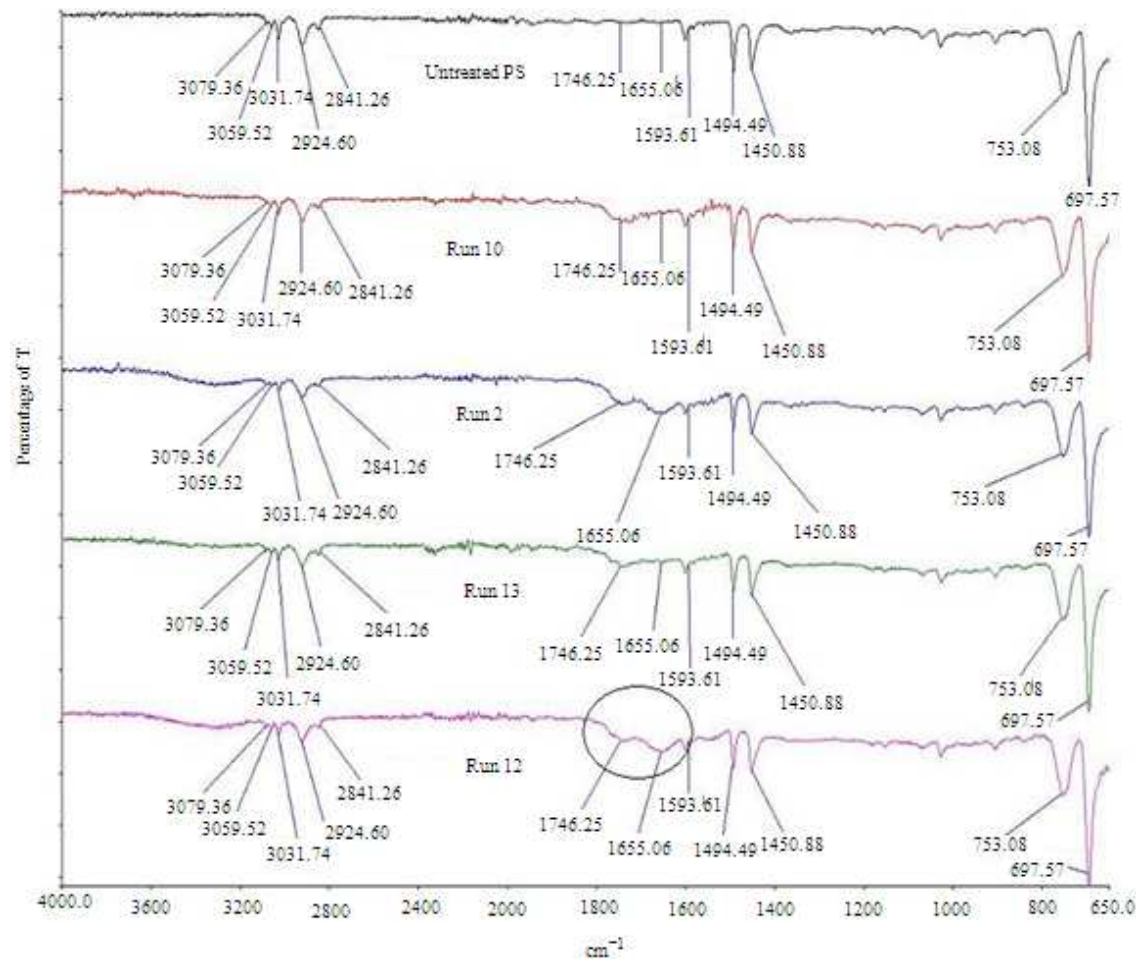

Fig. 3: FTIR of selected run of PS particle after UV/ozone surface modification and gelatin anchored 
FTIR data in Fig. 2 and 3 showed different functional groups existed on the treated PS surface as compared to untreated PS. Figure 2 shows the existence of peak at $1736.34 \mathrm{~cm}^{-1}$ which could be assigned to a new absorption peak due to carbonyl group $(\mathrm{C}=\mathrm{O}$ and $\mathrm{COOH})$ and Hydroxyl $(\mathrm{OH})$ group peak at $3450 \mathrm{~cm}^{-1}$ when samples were treated with UV/ozone at different condition. It was clearly observed in Fig. 3 the existence of amide I group (CONH) peak at band $1655.06 \mathrm{~cm}^{-1}$ and amide II $\left(\mathrm{NH}_{2}\right)$ group at $1541 \mathrm{~cm}^{-1}$ (Shen et al., 2007) for coated PS indicated the availability of bovine gelatin on PS particles. On the other hand, Fig. 2 shows FTIR data of untreated PS attributed only to the polar oxygen containing group on UV/ozone treated surface (Griffiths, 2000).

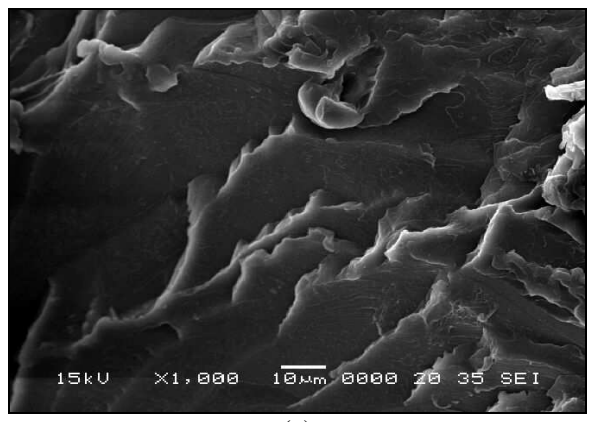

(a)

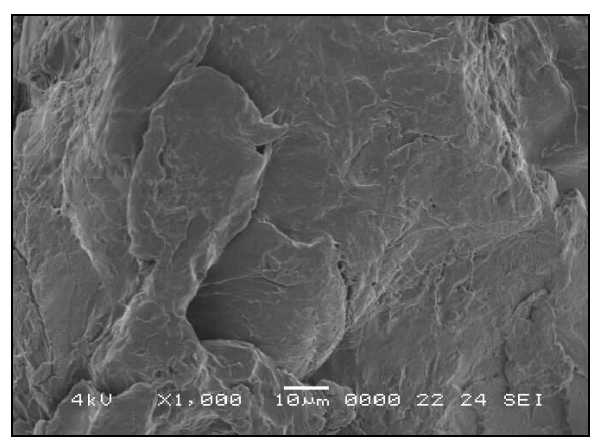

(b)

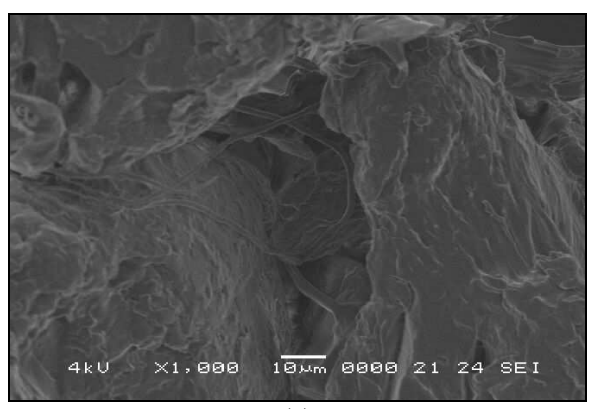

(c)

Fig. 4: SEM images of PS particle for Run 12. (a) untreated PS; (b) UV/ozone treated PS; (c) UV/ozone treated PS coated with gelatin
Small amount of gelatin on untreated PS surface thus showing no effect in FTIR data. Amide group peak was also identified at band $3310 \mathrm{~cm}^{-1}$ for Run 2 and 12 and its absence in Run 10 and 13 which clearly show that they have more available site to catch gelatin (Shen et al., 2007).

Scanning electron microscopy: Compared to untreated PS (Fig. 4a), SEM results at magnification of 1000X in Fig. 4 shows that the PS surface at Run 12 condition decreased in roughness after UV/ozone treatment (Fig. 4b). Thus, the result suggested that the ozone system can introduce aldehyde and carboxyl group with less degradation and roughening of the material. Figure $4 \mathrm{c}$ qualitatively identified the existence of gelatin fibers on the PS particle which were initially treated by UV/ozone system. It could be seen that the distribution of gelatin was not even but continued along the PS surface.

Reaction with water: Direct observation was done to determine hydrophilicity of PS particle. Figure 5a shows that untreated PS was hydrophobic in nature and tends to agglomerate while appear only on the surface of the liquid phase. Figure $5 \mathrm{~b}$ clearly shows the best treatment condition (Run 12) where the particles completely dispersed in distilled water reflected on a higher wet ability of PS particles and indicated the hydrophilic transformation of the polymer surfaces. Figure $5 \mathrm{c}$ showed most of the particles settled for coated PS particles as the density of the particle increased.

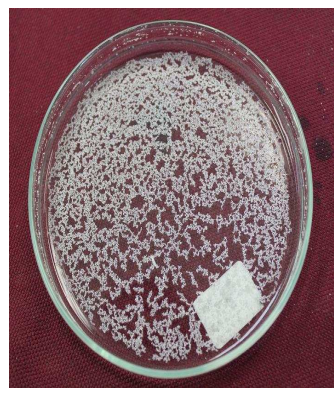

(a)

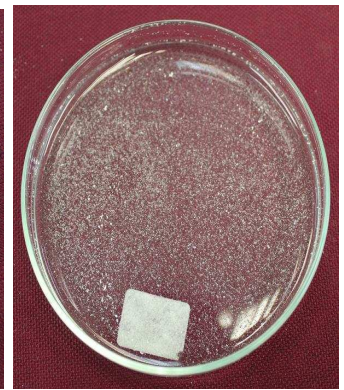

(b)

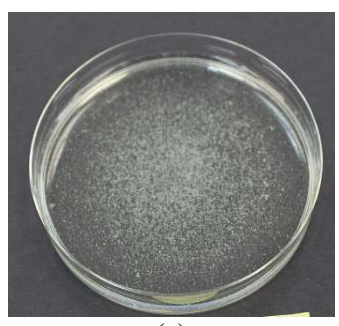

(c)

Fig. 5: Reaction of PS particle with distilled water, (a) untreated PS, (b) UV/ozone treated PS, (c) gelatin coated PS 


\section{DISCUSSION}

Thus, these data presented previously inferred that Run 12 contained the highest functionalized group (carbonyl group) that play significant role in binding protein to polymer surface (Greene et al., 2005) and the most effective condition to prepare PS surface for binding gelatin compared to other conditions suggested by the experimental design. Therefore, slight changes on time will affect the protein binding properties of the PS particle. It was reported that functional group responsible for protein immobilization increased with increasing treatment time (Murakami et al., 2003; Svorchik et al., 2002; Yanagisawa et al., 2006). Therefore, the best condition to produce required functional group must be studied in order to introduce the desired type and quantity of reactive functional groups (Goddard and Hotchkiss, 2007).

This phenomenon happens as ozone reacts again to the carbon double bond to introduce oxygen on the structure and thereby increases its wettability (Murakami et al., 2005; MacManus et al., 2000). Value of $\mathrm{R}^{2}$ is close to $100 \%$ indicates that the correlation between the experimental values of this experiment with the predicted values is high as shown in Table 2. Minimum time $(41.68 \mathrm{~min})$, flow rate $\left(1 \mathrm{~L} \mathrm{~min}^{-1}\right)$ and UV exposure $(6 \mathrm{~W})$ is important to reduce power and cost of the whole system. This possible optimum level of parameters for gelatin immobilization on functionalized PS is useful as not much information was available in the literature on this study.

The results concluded that gelatin immobilization, were considerably affected by varying exposure time at reduced flow rate and increased UV intensity. Increasing UV intensity helps cleavage of chemical bonds, creation of free radical and subsequent oxidation of irradiated materials and thus eases the process of surface modification (Svorchik et al., 2002). The interaction between term B and C (Fig. 1) on the other hand shows that optimum lower yield can be obtained when varying flow rate and UV. The densities obtained which is slightly higher than the density of water which enables them to be used in wider application such as microcarrier for animal cell culture (Tanyildizi et al., 2005).

Based on surface chemistry characterization (FTIR), it was found that the number of carbonyl group was decreased after gelatin coating indicated that the carbonyl group was able to bond with the amine group of gelatin. This explains that biospecific interactions can be developed between biological compounds and functionalized polystyrene particles with suitable chemical groups (Jozefowicz and
Jozefonvicz, 1997). Surface roughness is also an important parameter to determine the effect of surface treatment as it may effects many application where the smooth surface explained why the distribution of gelatin was not even but firmed on the treated PS surface. Furthermore, it was reported that moderate wet ability surfaces in which the water contact angle ranges from $55-65^{\circ}$ considerably adsorb proteins (Ma et al., 2007; Lee et al., 1998) compared to untreated PS which failed to provide reactivity where it is reported to have $90^{\circ}$ contact angle (Yanagisawa et al., 2006).

\section{CONCLUSION}

We examined the effect of surface modification of PS micro particles utilizing ozone/UV treatment on gelatin immobilization. PS particle having larger amount of gelatin on their surfaces have been successfully fabricated by a method of UV/ozone system under study. It was found that the model used was significant and Run 12 (45 min, $1 \mathrm{~L} \mathrm{~min}^{-1}, 18 \mathrm{~W}$ ) has been identified as the best condition to promote gelatin immobilization. The treatments, especially ozone/UV treatment, caused chemical modification through introduction of hydrophilic functional groups on the surfaces of PS particle.

\section{ACKNOWLEDGMENT}

Thanks to laboratory assistance and students from Animal Tissue Engineering Lab of Biotechnology Engineering IIUM and Plasma Laboratory UM for their excellent work.

\section{REFERENCES}

Bari, M.N., M.Z. Alam, S.A. Muyibi, P. Jamal and A.A. Mamun, 2009. Improvement of production of citric acid from oil palm empty fruit bunches: Optimization of media by statistical experimental designs. Bioresour. Technol., 100: 3113-3120. DOI: 10.1016/J.BIORTECH.2009.01.005

Chibata, I., 1979. Immobilized Enzyme-Research and Development. John Wiley and Sons, New York, ISBN: 0470265310, pp: 108-110.

Clark Jr., T., J.D. Ruiz, H. Fan, C.J. and Brinker et al., 2000. A new application of UV-ozone treatment in the preparation of substrate-supported mesoporous thin films. Chem. Mater., 12: 3879-3884. DOI: 10.1021/CM000456F

Davidson, M.R., S.A. Mitchell and R.H. Bradley, 2004. UV-Ozone modification of plasma polymerized acetonitrile films for enhanced cell attachment. Colloids Surf. B. Biointerf., 34: 213-219. DOI: 10.1016/J.COLSURFB.2004.01.008 
Goddard, J.M. and J.H. Hotchkiss, 2007. Polymer surface modification for the attachment of bioactive compound. Prog. Polymer Sci., 32: 698-725. DOI: 10.1016/J.PROGPOLYMSCI.2007.04.002

Gosnell, M.C. and H.A. Mottola, 1988. Determination of activity and amount of silica-immobilized penicillinase. J. Microchem., 37: 149-154. DOI: 10.1016/0026-265X(88)90182-8

Greene, G., H. Radhakrishna and R. Tannenbaum, 2005. Protein binding properties of surface modified porous polyethylene membranes. Biomaterials, 26: 5972-5982. DOI: 10.1016/J.BIOMATERIALS.2005.03.025

Griffiths, B., 2000. Animal cell culture. A practical approach. 3rd Edn., Oxford University Press, Oxford, UK., ISBN: 0199637970, pp: 58-62.

Jozefowicz, M. and J. Jozefonvicz, 1997. Randomness and biospecificity: Random copolymers are capable of biospecific molecular recognition in living systems. Biomaterials, 18: 1633-44. DOI: 10.1016/S0142-9612(97)00145-2

Kang, H.W., Y. Tabata and Y. Ikada, 1999. Fabrication of porous gelatin scaffolds for tissue engineering. Biomaterials, 20: 1339-1344. DOI: 10.1016/S0142-9612(99)00036-8

Lee, J.H., G. Khang, J.W. Lee and H.B. Lee, 1998. Interaction of different types of cells on polymer surfaces with wettability gradient. J. Colloid Interface Sci., 205: 323-330. DOI: 10.1006/JCIS.1998.5688

Lu, X., D. Li, Y. Huang and Y. Zhang, 2007. Application of a modified Coomassie brilliant blue protein assay in the study of a protein adsorption on carbon thin films. Surf. Coating Technol., 201: 6843-6846. DOI: 10.1016/J.SURFCOAT.2006.09.019

Ma, Z., Z. Mao and C. Gao, 2007. Surface modification and property analysis of biomedical polymers used for tissue engineering. Colloids Surf. B., 60: 137-157. DOI: 10.1016/J.COLSURFB.2007.06.019

MacManus, L.F., M.J. Walzak and N.S. McIntyre, 2000. Study of ultraviolet light and ozone surface modification of polypropylene. J. Polymer Sci. Polymer Chem., 37: 2489-2501. DOI: 10.1002/(SICI)10990518(19990715)37:14<2489:: AID-POLA23>3.0.CO;2-G

Mao, J.S., L.G. Zhao, Y.J. Yin and K.D. Yao, 2003. Structure and properties properties of bilayer chitosan-gelatin scaffolds. Biomaterials, 24: 1067-1074. DOI: $10.1016 / \mathrm{S} 01429612(02) 00442-8$
Mengyan, L., K.M. David, C. Tianhong and J.M. Michael, 2005. Cellular response to gelatin and fibronectin coated multilayer polyelectrolyte nanofilms. IEEE Trans. Nanobiosci., 4: 170-179. PMID: 16117025

Murakami, T.N., Y. Fukushima, Y. Hirano, Y. Tokuoka and M. Takahashi et al., 2005. Modification of PS films by combined treatment of ozone aeration and UV irradiation in aqueous ammonia solution for the introduction of amine and amide groups on their surface. Appl. Surf. Sci., 249: 425-432. DOI: 10.1016/J.APSUSC.2004.12.017

Murakami, T.N., Y. Fukushima, Y. Hirano, Y. Tokuoka and M. Takahashi et al., 2003. Surface modification of polystyrene and poly (methyl methacrylate) by active oxygen treatment. Colloids Surf. B: Biointerf., 29: 171-179. DOI: 10.1016/S0927-7765(02)00189-3

Orschel, M., A. Katerkamp, M. Meusel and K. Cammann, 1998. Evaluation of several methods to quantify immobilized proteins on gold and silica surfaces. Colloids Surf. B. Biointerf., 10: 273-279. DOI: 10.1016/S0927-7765(98)00008-3

Saltzman, M. and T.R. Kyriakides, 2007. Cell Interaction with Polymers. 3rd Edn., Elsevier Science, USA., pp: 279- 296.

Shen, H., X. Hu, F. Yang, J. Bei and S. Wang, 2007. Combining oxygen plasma treatment with anchorage of cationized gelatin for enhancing cell affinity of poly (lactide-co-glycolide). Biomaterials, 28: 4219-4290. DOI: 10.1016/J.BIOMATERIALS.2007.06.004

Svorchik, V., R. Rockova, B. Dvorankova, L. Broz and V. Hnatowicz et al., 2002. Cell adhesion on modified polyethylene. J. Mater. Sci., 37: 1183-1188. DOI: 10.1023/A:1014319522689

Tanyildizi, M.S., O. Dursun and E. Murat, 2005. Optimization of a-amylase production by Bacillus sp. using response surface methodology. Process Biochem., 40: 2291-2297. DOI: 10.1016/J.PROCBIO.2004.06.018

Teare, D.O.H., N. Emmison, C. Ton-That and R.H. Bradley, 2001. Effect of serum in the kinetics of $\mathrm{CHO}$ attachment to ultraviolet-ozone modified polystyrene surface. J. Colloid. Interf. Sci., 234: 84-89. DOI: 10.1006/JCIS.2000.7282

Yanagisawa, K., T.N. Murakami, Y. Tokuoka, A. Ochiai and M. Takahashi et al., 2006. Immobilization and enzymatic activity of glucose oxidase on polystyrene surface modified with ozone aeration and UV irradiation in distilled water and aqueous ammonia solution. Colloids Surf. B: Biointerf., 48: 67-71. DOI: 10.1016/J.COLSURFB.2006.01.008 